\title{
IS THERE ROOM FOR THE BBC IN THE MENTAL LEXICON? \\ ON THE RECOGNITION OF ACRONYMS
}

\author{
Marc Brysbaert $^{1,2}$, Sara Speybroeck ${ }^{1,2}$, Dieter Vanderelst ${ }^{1,2}$ \\ ${ }^{1}$ Ghent University, Belgium \\ ${ }^{2}$ Royal Holloway, University of London
}

Address: $\quad$ Marc Brysbaert

Department of Experimental Psychology

Ghent University

Henri Dunantlaan 2

B-9000 Gent, Belgium

Tel. +3292649425

Email: marc.brysbaert@ugent.be

Keywords: mental lexicon, acronym, masked priming, associative priming, word recognition 


\section{AbSTRaCT}

It has been suggested that familiar, orthographically illegal acronyms like BBC are processed like real words. This claim has been based on improved performance with acronyms in the Reicher-Wheeler task, the letter string matching task, the visual feature integration task, and the N400 component in ERP studies. Unfortunately, in all these tasks performance on acronyms resembled performance on pseudowords more than performance on words. To further assess the similarity of acronyms and words, we used masked priming to see whether it was possible to prime target words with associatively related acronyms to the same extent as with associatively related words. Such priming was possible at an SOA of $84 \mathrm{~ms}$. In addition, the priming of the acronyms did not depend on the letter case in which they were presented. 


\section{IS THERE ROOM FOR THE BBC IN THE MENTAL LEXICON?}

\section{ON THE RECOGNITION OF ACRONYMS}

Everyone who ever lived in the UK has been bewildered by the omnipresence of abbreviations. For instance, foreigners trying to register their used car, must pass MOT (not to be confounded with MOD) and send letters to DVLA, hoping they will end up with the desired V5C (not to be mistaken for VIC) rather than the dreaded SORN. Similarly, helpful universities provide their new staff with lists of the most common abbreviations they have to know for proper functioning (especially those related to health and safety).

A search through the internet (see in particular http://en.wikipedia.org/wiki/Acronym, retrieved on 15 August 2008) suggests that although abbreviations have been around for a long time (think of $\mathrm{AD}$ and $\mathrm{BC}$ ), the surge in their usage is a typical $20^{\text {th }}$ century phenomenon. Abbreviations consisting of the first letters of a fixed expression are usually called acronyms. Originally, this name was limited to abbreviations with orthographically legal letter sequences than could be pronounced (such as NATO, VOSA, HOMER), whereas illegal letter sequences (DVLA, RSPCA) were called initialisms. Gradually, however, authors started to use the term acronym for all letter sequences consisting of initial letters.

The existence of acronyms raises the question how they are recognised by the brain: Are they processed like words or like pictures? In 1964, Gibson, Bishop, Schiff, and 
Smith showed that acronyms were more likely to be identified in a perceptual identification task than meaningless letter strings of the same length, but such a finding is in line both with the idea of an acronym as a word and with the hypothesis of an acronym as a picture. Research on the question experienced some further popularity in the 1970s and 1980s, when researchers tried to understand the specifics of two popular tasks at the time.

The first paradigm was the Reicher-Wheeler task. In this paradigm, participants had to identify a letter in a letter string. The most important finding was that letter identification was better when the letter was part of a word (e.g. "F" in FIB) than when it was part of an illegal letter string (e.g., "F" in BFI). This is the so-called word superiority effect (WSE). To understand the mechanisms underlying the WSE, researchers compared letter identification for pseudowords (letter strings that did not form a word but that followed the orthographic rules of the language; e.g., BIF) and illegal letter strings that were familiar acronyms (FBI). Pseudowords were used because they allowed researchers to test the importance of orthographic legality; acronyms were used because they allowed researchers to test the impact of stimulus familiarity.

The usual finding was that both pseudowords and acronyms resulted in better letter identification than illegal, unfamiliar letter strings (e.g., Besner, Davelaar, Alcott, \& Parry, 1984; Noice \& Hock, 1987; see also Staller \& Lappin, 1981 for a related task). Surprisingly, none of these studies included all the conditions. Such a study was published only recently. Laszlo and Federmeier (2007a) compared letter identification in words (DUCT), pseudowords (DAWK), acronyms (HDTV), and illegal letter 
strings (GHTS). They obtained percentages of identification of respectively $88 \%$, $84 \%, 77 \%$, and $73 \%$.

The second paradigm in which acronyms were used was letter string matching. Two strings of letters were presented simultaneously and participants had to indicate whether the strings were the same or different. The most robust finding in this paradigm again was that participants were faster to make a decision when the stimuli were familiar words than when they were illegal letter strings. As in the ReicherWheeler task, pseudowords and acronyms were used to decide whether the word superiority effect was due to orthographic legality or to familiarity. A typical example is provided by Carr, Posner, Pollatsek, and Snyder (1979, Experiment 1). They compared the times needed to decide that letter strings like FIB-FIB, BIF-BIF, FBIFBI, and IBF-IBF were the same. They obtained response times of respectively 534, 541, 565, and $593 \mathrm{~ms}$, again showing effects of both orthographic regularity and familiarity. Other researchers using this task were Henderson (1974), Henderson and Chard (1976), Seymour and Jack (1978) and Besner (1984).

On the basis of the above findings, researchers concluded that acronyms were processed like words and were part of the mental lexicon, despite their orthographic illegality (e.g., Coltheart, 1978; Besner et al., 1984). Besner et al. (1984) added two more pieces of evidence for this conclusion. First, acronyms were recognised better in the right visual field than in the left visual field, in line with words and in contrast to logographs. Second, participants could report more letters from tachistoscopically presented acronyms than from meaningless control stimuli, also when the acronyms 
were presented in a distorted format by changing the size of one of the letters (e.g. $\mathrm{FBI})$.

Further evidence for the idea that acronyms were recognised like words was published by Prinzmetal and Millis-Wright (1984). They started from the finding that participants more often misattribute a letter's colour in words than in nonwords. For instance, participants were given the stimulus AGE or VGH and asked to name the colour of the letter $\mathrm{G}$ (each letter had a different colour). When the stimulus was a word, participants erroneously gave the colour of another letter in $9.3 \%$ of the trials; with nonwords stimuli this was only so in $5.2 \%$ of the trials (Experiment 1). A similar asymmetry was observed for acronyms $(11.8 \%)$ vs. matched meaningless letter sequences (8.5\%; Experiment 4).

Research on acronyms recently knew a small revival with the work of Laszlo and Federmeier, who used these stimuli in event-related potential (ERP) experiments. In these experiments the electric brain response to different types of stimuli is registered. An interesting finding here is that the response to words differs reliably from the response to illegal letter strings. In particular, a negative-going deflection around 400 ms (the so-called N400 component) is much stronger for words than for illegal letter strings. A useful design to examine this difference is repetition priming. In this design, the stimuli are presented twice with some trials in-between. The usual finding is that the N400 component for words is much smaller the second time than the first time, whereas there is no difference for illegal letter strings. So, by calculating the difference in $\mathrm{N} 400$ between the first and the second presentation, researchers can easily compare the extent to which other stimuli resemble words or illegal letter 
strings. In line with previous experiments, Laszlo and Federmeier (2007b) looked at the repetition priming effects for words, pseudowords, acronyms, and illegal letter strings. The effects were respectively $-1.2 \mu \mathrm{V}$ for words, $-1.4 \mu \mathrm{V}$ for pseudowords, $1.9 \mu \mathrm{V}$ for acronyms, and $-.3 \mu \mathrm{V}$ for illegal letter strings. Interestingly, when the participants did not know the acronyms, they did not show a repetition priming effect for these stimuli either. Laszlo and Federmeier (2008) later replicated the findings in a related design in which words or acronyms were primed or not by the preceding sentence context.

On the basis of the above findings it would seem safe to assume that the British mental lexicon indeed has room for an acronym like the $\mathrm{BBC}$, even though it violates the English orthography in various ways (e.g., no English word lacks a vowel, no English word starts with BB or ends on BC). Unfortunately, to a sceptical eye the evidence is less convincing than hoped for.

The main problem is that all the acronym-related effects listed above are obtained with pseudowords as well. This was true for the word superiority effect in the Reicher-Wheeler task, for the word superiority effect in the letter string matching paradigm, for the colour migrations of Prinzmetal and Millis-Wright (1984; see their Experiment 3), and for the N400 priming effects reported by Laszlo and Federmeier (although in the latter case the ERP signal of acronyms overall resembled that of words more than that of pseudowords). Given that pseudowords are not represented in the mental lexicon, this raises the question what exactly causes the difference between acronyms and illegal letter strings. Carr et al. (1979), for instance, argued that in the letter string matching task the difference was due to a shift in the response criterion as 
a result of stimulus familiarity (participants were faster to respond "same" to familiar stimuli than to unfamiliar stimuli, even before identifying the specific stimuli presented).

A further problem is that there is quite some evidence that acronyms are better processed in their familiar uppercase format than in an unfamiliar format. For instance, Besner et al. (1984; table 9.4) observed that participants identified tachistoscopically presented acronyms like FBI more often than meaningless control sequences like IBF (56\% identification vs. 52\% identification). However, no such superiority was found for acronyms presented in lowercase; there was even a trend in the reverse direction ( $50 \%$ for fbi vs. $52 \%$ for ibf). Similarly, Seymour and Jack (1978) reported a strong effect of letter case for acronyms in a letter string matching task. Participants were faster to indicate that letter strings like RAF-RAF and USAUSA were the same $(717 \mathrm{~ms})$ than to indicate that letter strings like raf-raf and usausa were the same $(771 \mathrm{~ms})$. No similar effect was found for meaningless control strings (807 ms vs. 806 ms). Along the same lines, Hall, Humphreys, and Cooper (2001) reported a patient with attentional dyslexia who could name more acronyms in uppercase (10/40) than in lowercase (5/40). In contrast, he read more words in lowercase (47/60) than in uppercase (37/60). The patient also named more acronyms without spaces between the letters (e.g., GCSE; 27/39) than acronyms with two blank spaces between the letters (G C S E; 20/39).

The fact that acronym processing differs between uppercase and lowercase format, contrasts with results from research on visual word recognition. A typical finding here is that letter case is of minor importance. For instance, Rayner, McConkie, and Zola 
(1980) found no difference in reading speed when participants saw the upcoming words in parafoveal vision in the same case as later in foveal vision or in a different case. Apparently, before written word identification starts, the visual input is translated into abstract letter identifiers, which allow readers to recognise words independently of the font in which they are written.

All in all, although the evidence for lexical processing of acronyms is suggestive, it would be good if the presumed similarity between acronyms and words could be extended to another paradigm. A task that currently is used a lot within visual word recognition is masked priming (e.g., Kinoshita \& Lupker, 2003). In this paradigm, a target word is preceded by a prime presented so briefly (typically for around $50 \mathrm{~ms}$ ) that the participant cannot identify it. Still, the prime influences the processing of the target.

Particularly interesting for the present topic is masked associative priming. In this paradigm, target words are preceded by primes that are associatively related. Associatively related words are words that participants spontaneously report as the first word that comes to mind upon hearing a probe word (e.g., boy-girl). The general finding is that target words are processed faster after associatively related primes than after unrelated control primes. For instance, Lukatela and Turvey (1994) reported that the naming latency for the target word "frog" was 20 ms faster when it was primed by "TOAD” than when it was primed by "TOLLED”. Drieghe and Brysbaert (2002) repeated this finding and extended it to a lexical decision task (i.e., participants had to decide whether the target stimulus was a word or not). Alameda, Cuetos, and 
Brysbaert (2003) further showed that associative priming is not limited to words, but can also be observed with numbers as targets (e.g. Boeing - 747). ${ }^{1}$

In the experiment below we compared associative priming with acronyms and words. A first list of target words was primed with associatively related words (e.g., FIB LIE) and with matched unrelated words (e.g. HIM - LIE). A second list of words was primed with associatively related acronyms (e.g., BLT - SANDWICH) or with matched unrelated acronyms (STN - SANDWICH). In addition, the related primes could be presented in uppercase (FIB, BLT), in lowercase (fib, blt), or in mixed case (fIb, bLt). The predictions were straightforward: If acronyms had the same lexical representations as words, we expected to find the same priming effects with acronyms as with words.

\section{Experiment}

\section{Method}

\section{Participants}

A group of 24 undergraduate students from Royal Holloway, University of London took part in the experiment in exchange of course credit. All participants were native speakers of English and had normal or corrected-to normal vision.

\footnotetext{
${ }^{1}$ Although the associative priming effect is well-estiablished, there is still discussion about its theoretical interpretation, in particular to what extent the effect is due to semantic feature overlap between prime and target, to functional relationships between prime and target, and to the cooccurrence of prime and target in texts and discourse (see Bueno \& Frenck-Mestre, 2008; Hutchison, 2003; Lucas, 2000; and Perea \& Rosa, 2002, for further discussion).
} 


\section{Stimulus material}

The experimental stimuli consisted of 96 prime-target pairs (see the Appendix). Half of the primes were acronyms; the other half were words. All targets were words. For each target there was a related and an unrelated prime. The unrelated primes were obtained by swapping related primes and targets. The related primes could be displayed in uppercase, in lowercase, or in mixed case. The unrelated primes were always displayed in uppercase (as we had no predictions concerning case differences for this type of primes).

The acronyms were selected from an undergraduate student's research project in which students at Royal Holloway had been presented with a list of 170 familiar acronyms (James, 2004). They were asked to write down the first associate that came to mind. Out of this list, the 48 acronyms with the most frequent associates were chosen. The average association strength was $71.9 \%$. The acronym primes were 2 to 5 letters long and their associated targets were 3 to 12 letters long. The 48 word primes were selected from the Edinburgh Associative Thesaurus (Kiss et al., 1973). The word primes and targets were matched with the acronym primes and targets in association strength and in length. Four lists were created according to a Latin-square design, each including 96 prime-target pairs, so that no participant saw a prime or a target twice. Each participant was presented with one of the four lists.

The filler stimuli consisted of 96 matched pairs of primes and non-word targets. Half of the filler primes were acronyms; the other half were words. The primes of the filler trials were presented in the same case as those of the test trials (i.e., $1 / 2$ uppercase, $1 / 4$ lowercase, and $1 / 4$ mixed case). The filler stimuli had been made by starting from 
prime-target pairs similar to those used in the test trials, and then changing a letter of the target, so that it became a legal nonword.

Each participant was presented with a total of 192 prime-target pairs. A practice session containing 20 prime-target pairs preceded the actual experiment. All stimuli were presented in black on a white background and printed in a bold Times New Roman font (12 pts). The targets were always presented in uppercase letters.

\section{Procedure}

Participants were tested individually. Stimulus presentation and response measurement were controlled by the DMDX software (Forster \& Forster, 2003). All stimuli were presented at the centre of a 14 inch screen. On each trial, a forward mask was presented on the screen for $300 \mathrm{~ms}$. The mask consisted of 14 "\#" signs and had the same size and font as the prime and the target. Then the prime was displayed for $48 \mathrm{~ms}$ followed by a backward mask for $36 \mathrm{~ms}$ (making the total stimulus onset asynchrony equal to $48+36=84 \mathrm{~ms})^{2}$. The backward mask consisted of 14 "\#” signs and had the same font as the forward mask but a bigger size (13 pts). After presentation of the backward mask, the target was displayed and stayed on the screen until the participant made a response.

Participants were asked to decide as quickly and as accurately as possible whether the string they saw was a real English word or a non-word by pressing the right and left

\footnotetext{
${ }^{2}$ It is not clear how critical this SOA is. James (2004) found priming with acronyms at an SOA of 50 ms (only including related vs. unrelated uppercase primes), but in at least two unpublished experiments we were unable to replicate this finding with SOAs of $48 \mathrm{~ms}$. In all likelihood, whether or not it is possible to obtain significant priming with acronyms at SOAs below $50 \mathrm{~ms}$ depends on the brightness (or the overall energy) of the primes (Tzur \& Frost, 2007).
} 
shift key respectively. The participants were not informed about the presence of the primes. Each participant received a different permutation of the stimulus list.

\section{Results}

Four items with word primes (see * in Appendix A) were omitted from the analysis because the average percentage of errors $(76 \%)$ on these items was too high. Incorrect responses (3.3\%) and reaction times less than $200 \mathrm{~ms}$ or greater than 1500 ms $(0.2 \%)$ were excluded from the latency analysis. The analyses were run across participants (F1 analysis) and across items (F2 analysis). Reaction times of the correct responses and percentages of errors were submitted to separate analyses of variance (ANOVAs) based on a 2 ("Prime type": acronym or word) $\times 4$ ("Relatedness condition": related uppercase, related lowercase, related mixed case, and unrelated to the target) design. Mean reaction times (RTs) and percentage of errors are given in Table 1.

Insert Table 1 about here

\section{RT analysis}

There was a significant main effect of Prime type $[\mathrm{F} 1(1,23)=11.19, \mathrm{MSe}=2418, \mathrm{p}$ $<.01 ; \mathrm{F} 2(1,84)=3.80, \mathrm{MSe}=11150, \mathrm{p}<.06]$ and of Relatedness condition $[\mathrm{F} 1(3$, $69)=7.73, \mathrm{MSe}=1431, \mathrm{p}<.01 ; \mathrm{F} 2(3,252)=6.61, \mathrm{MSe}=3087, \mathrm{p}<.01]$, but no 
interaction between both variables $[\mathrm{F} 1(3,69)=.09, \mathrm{MSe}=1859 ; \mathrm{F} 2(3,252)=.27$, MSe = 3087). Planned comparisons for the acronyms showed that the differences between each of the related conditions (uppercase, lowercase, and mixed case) and the unrelated condition were significant (all p1s $<.03$, all $\mathrm{p} 2 \mathrm{~s}<.05)$ and that there were no reliable differences between the related conditions $(\mathrm{F} 1<1 ; \mathrm{F} 2<1)$.

To make sure that the priming effect of the acronyms was not due to the primes that were orthographically legal (e.g., AOL, ABS, CAB, BAFTA), we ran an extra F2 analysis limited to the 28 related acronyms that were illegal (i.e., ABC, GCSE, BLT, BMW, ...; see the Appendix). For these stimuli, there was a $25 \mathrm{~ms}$ difference between the related $(M=603 \mathrm{~ms})$ and the unrelated primes $(M=628 \mathrm{~ms})$, which was next to significant in the usual two-tailed F-test $[\mathrm{F} 2(1,24)=3.85, \mathrm{MSe}=2215, \mathrm{p}<.062]$. As in the overall analysis, there were no significant differences between the related primes $[\mathrm{F} 2(2,48)=.84, \mathrm{MSe}=3642)$.

\section{Error analysis}

The main effect of Prime type was significant in the analysis by participants [F1 (1, $23)=63.7, \mathrm{p}<.01 ; \mathrm{F} 2(1,84)=3.04, \mathrm{p}>.08]$. The percentage of errors was higher for the list of target words preceded by word primes than for the list of target words preceded by acronyms. No other effect was significant.

\section{Discussion}


In this paper we investigated whether visual acronyms are processed like written words or like pictures. We did so by comparing the masked priming effect of associatively related acronyms with that of associatively related words. In addition, we manipulated the letter case of the related primes, to see whether the priming effect of acronyms would be limited to the familiar uppercase format.

We first replicated the masked associative priming effect with word primes previously reported by Lukatela and Turvey (1994) and Drieghe and Brysbaert (2002): Participants were about $30 \mathrm{~ms}$ faster to decide that the target was a word when it was preceded by an associatively related prime word than when it was preceded by an unrelated prime word. In addition, as expected we found the same priming effect for primes presented in lowercase, uppercase or mixed case.

More importantly, we obtained exactly the same priming effects for acronym primes. Not only was the effect of the same size, but it also did not depend on whether the acronyms were presented in their familiar format (uppercase) as whether they were presented in unfamiliar formats (lowercase or mixed case). This finding is particularly convincing for the lexical processing of acronyms. As mentioned in the introduction, there is quite some evidence that acronyms as targets in a perceptual identification task or a string matching task are more easily processed in their familiar uppercase format than in lowercase format (Besner et al., 1984; Hall et al., 2001; Seymour \& Jack, 1978). However, this does not seem to be the case for the automatic processes tapped into by the masked priming paradigm. The masked priming effect for associatively related acronyms in all likelihood relies on the same abstract letter identifiers as the masked priming effect for associatively related words. 
The fact that acronyms like BBC are part of the mental lexicon suggests that orthographic legality is no prerequisite for inclusion (also see the analysis limited to the illegal acronyms in the results section). This raises an interesting question. Given that there are strong connections between orthographic and phonological word representations and that phonological information is involved in visual word recognition, how then does the phonological code of illegal acronyms look like?

This issue was recently addressed by Slattery, Pollatsek, and Rayner (2006). They reasoned that the phonological representation of BBC might simply be the threesyllable word BeeBeeCee. To test this idea, they made use of the fact that the indefinite article in English is "a" before a consonant and "an" before a vowel. So, would readers prefer "a FBI agent" or "an FBI agent"? Similarly, would they prefer "a USA official" or "an USA official"? Slattery et al. (2006) investigated the issue by tracking the eye movements of students reading sentences that contained those sequences. In line with their hypothesis, Slattery et al. found consistently shorter first fixation durattions for phonological consistent pairings like "an FBI agent" and "a USA official" than for phonological inconsistent pairings like "a FBI agent" and "an USA official”.

So, there is some evidence that orthographically illegal acronyms have their own multisyllabic phonological representation consisting of the full letter names. This too is in line with the idea that there is room in the British lexicon for "words" like BBC, DVLA, V5C, RSPCA, HBSC (and hundreds more). Whether this may be interpreted 
as an encouragement to further increase the number of acronyms in the English language is a different matter that cannot be addressed on the basis of the present data. 


\section{References}

Alameda, J.R., Cuetos, F., \& Brysbaert, M. (2003). The number 747 is named faster after seeing Boeing than after seeing Levi's: Associative priming in the processing of multidigit Arabic Numerals. Quarterly Journal of Experimental Psychology, 56A, 1009-1019.

Besner, D. (1984). Specialized processors subserving visual word recognition: Evidence for local control. Canadian Journal of Psychology, 38, 94-101.

Besner, D., Davelaar, E., Alcott, D., \& Parry, P. (1984). Wholistic reading of alphabetic print: Evidence from the FDM and the FBI. In L. Henderson (Ed.), Orthographies and reading: Perspectives from cognitive psychology, neuropsychology and linguistics. Hillsdale, NJ: Erlbaum.

Bueno, S. \& Frenck-Mestre, C. (2008). The activation of semantic memory: Effects of prime exposure, prime-target relationship, and task demands. Memory \& Cognition, 36, 882-898.

Carr, T.H., Posner, M.I., Pollatsek, A., \& Snyder, C.R.R. (1979). Orthography and familiarity effects in word processing. Journal of Experimental Psychology: General, 108, 389-414.

Coltheart, M. (1978). Lexical access in simple reading tasks. In G. Underwood (Ed.). Strategies of information processing (pp. 151-216). London: Academic Press.

Drieghe, D., \& Brysbaert, M. (2002). Strategic effects in associative priming with words, homophones, and pseudohomophones. Journal of Experimental Psychology: Learning, Memory, and Cognition, 28, 951-961.

Forster, K.I., \& Forster, J.C. (2003). A Windows display program with millisecon accuracy. Behavior Research Methods, Instruments, \& Computers, 35, 116124.

Gibson, E.J., Bishop, C.H., Schiff, W., \& Smith, J. (1964). Comparison of meaningfulness and pronounceability as grouping principles in the perception and rentention of verbal material. Journal of Experimental Psychology, 67, 173-182.

Hall, D.A., Humphreys, G.W., \& Cooper, A.C.G. (2001). Neuropsychological evidence for case-specific reading: Multi-letter units in visual word recognition. Quarterly Journal of Experimental Psychology, 54A, 439-467.

Henderson, L. (1974). A word superiority effect without orthographic assistance. Quarterly Journal of Experimental Psychology, 20, 301-311.

Henderson, L., \& Chard, J. (1976). On the nature of the facilitation of visual comparisons by lexical membership. Bulletin of the Psychonomic Society, 7, 432-434.

Hutchison, K.A. (2003). Is semantic priming due to association strength or feature overlap? A microanalytic review. Psychonomic Review \& Bulletin, 10, 785813.

James, C. (2004). A connection is made: Masked associative priming using abbreviations. Unpublished $3^{\text {rd }}$ year project. Royal Holloway, University of London.

Kinoshita, S., \& Lupker, S.J. (2003). Masked priming: State of the art. Hove, UK: Psycholgoy Press.

Kiss, G.R., Armstrong, C., Milroy, R., \& Piper, J. (1973) An associative thesaurus of English and its computer analysis. In Aitken, A.J., Bailey, R.W. and Hamilton-Smith, N. (Eds.), The Computer and Literary Studies. Edinburgh: 
University Press.

Laszlo, S., \& Federmeier, K.D. (2007a). The acronym superiority effect. Psychonomic Bulletin \& Review, 14, 1158-1163.

Laszlo, S., \& Federmeier, K.D. (2007b). Better the DVL you know: Acronyms reveal the contribution of familiarity to single word reading. Psychological Science, $18,122-126$.

Laszlo, S., \& Federmeier, K.D. (2008). Minding the PS, queues, and PXQs: Uniformtiy of semantic processing across multiple stimulus types. Psychophysiology, 45, 458-466.

Lucas, M. (2000). Semantic priming without association: A meta-analytic review. Psychonomic Bulletin \& Review, 7, 618-630.

Lukatela, G., \& Turvey, M.T. (1994). Visual lexical access is initially phonological. 1. Evidence from associative priming by words, homophones, and pseudohomophones. Journal of Experimental Psychology: General, 123, 107128.

Noice, H., \& Hock, H.S. (1987). A word superiority effect with nonorthographic acronyms: Testing for unitized visual codes. Perception \& Psychophysics, 42, 485-490.

Perea, M., \& Rosa, E. (2002). The effects of associative and semantic priming in the lexical decision task. Psychological Research, 66, 180-194.

Prinzmetal, W., \& Millis-Wright, M. (1984). Cognitive and linguistic factors affect visual feature integration. Cognitive Psychology, 16, 305-340.

Rayner, K., McConkie, G.W., \& Zola, D. (1980). Integrating information across eye movements. Cognitive Psychology, 12, 206-226.

Seymour, P.H., \& Jack, M.V. (1978). Effects of visual familiarity on "same" and "different" decision processes. Quarterly Journal of Experimental Psychology, 30, 455-469.

Slattery, T.J., Pollatsek, A., \& Rayner, K. (2006). The time course of phonological and orthographic processing of acronyms in reading: Evidence from eye movements. Psychonomic Bulletin \& Review, 13, 412-417.

Staller, J.D., \& Lappin, J.S. (1981). Visual detection of multi-letter patterns. Journal of Experimental Psychology: Human Perception and Performance, 7, 12581272.

Tzur, B., \& Frost, R. (2007). SOA does not reveal the absolute time course of cognitive processing in fast priming experiments. Journal of Memory and Language, 56, 321-335. 
Table 1 : Mean RTs (in ms), percentage of erros, and standard deviations (in parentheses) of the Experiment.

\begin{tabular}{lllllllll}
\hline Type & \multicolumn{1}{l}{ Related upper } & \multicolumn{2}{l}{ Related lower } & \multicolumn{2}{l}{ Related mixed } & \multicolumn{2}{l}{ Unrelated } \\
& RT & Error & RT & Error & RT & Error & RT & Error \\
& & & & & & & & \\
\hline Acronym & $604(71)$ & $0.3(1.7)$ & $598(72)$ & $3.5(6.0)$ & $600(68)$ & $2.8(4.7)$ & $631(85)$ & $3.5(4.9)$ \\
Word & $583(54)$ & $8.4(7.8)$ & $578(73)$ & $12.3(10.2)$ & $571(48)$ & $8.4(10.4)$ & $607(78)$ & $11.4(10.8)$ \\
\hline
\end{tabular}




\section{Appendix}

Stimuli used in the experiments

\section{Acronyms}

Primes

Related Related Related Unrelated

Target

Assoc.

Upper

Lower Mixed

$\mathrm{ABC} \quad \mathrm{abc}$

ABS abs

AOL aol

BAFTA bafta

BLT blt

BMW bmw

BMX bmx

$\mathrm{aBc}$

$\mathrm{aBs}$

$\mathrm{aOl}$

RSPCA

VCR

VIP

bAfTa

GCSE

bLt

STN

BP bp

bMw

UHT

BRO bro

bMx

KFC

CAB cab

bP

ISBN

CNN cnn

bRo

NBA

$\mathrm{cAb}$

SMS

DOA doa

$\mathrm{cNn}$

MTV

DVLA

dvla

$\mathrm{dOa}$

LAPD

FC fc

dVlA

$\mathrm{H} 2 \mathrm{O}$

FM fm

GCSE gcse

fC

IT

$\mathrm{H} 2 \mathrm{O}$ h2o

fM

HGV hgv

$\mathrm{gCsE}$

USA

HQ hq

HSBC hsbc

h2o

BAFTA

DVLA

$\mathrm{hGv}$

TA

hQ

$\mathrm{hSbC}$

iSbN

TV

ISBN isbn

$$
\text { iT }
$$

KFC kfc

$\mathrm{kFc}$

USSR

BP

LAPD lapd

$$
\text { 1ApD }
$$

FC

LED led

IEd

MAX max

$\mathrm{mAx}$

MTV mtv

mTv

BMX

DOA

NBA nba

$\mathrm{nBa}$

VAT

NY

NSPCC

nspec

$\mathrm{nSpCc}$

CNN

NY ny

OAP

oap

nY

BRO

PO po

RSPCA rspca

SMS sms

SOS sos

STATS stats

oAp

pO

UCI

MAX

SOS

rSpCa

WC

sMs

$\mathrm{ABC}$

$\mathrm{CAB}$

sOs

STN stn

sTaTs

OAP

UCAS

TA ta

sTn

BLT

tA

HGV

TV

tV

HQ

UCAS ucas uCaS

STATS

ALPHABET

$62^{+}$

BRAKES 60

INTERNET $\quad 60$

AWARD 68

SANDWICH $\quad 64^{+}$

CAR $90^{+}$

BIKE $84^{+}$

PETROL $72^{+}$

BROTHER $\quad 80$

TAXI 78

NEWS $\quad 68^{+}$

DEAD $\quad 56$

DRIVING $\quad 64^{+}$

FOOTBALL $\quad 80^{+}$

RADIO $80^{+}$

EXAM $\quad 70^{+}$

WATER $\quad 100^{+}$

LORRY $56^{+}$

HEADQUARTERS $68^{+}$

BANK $86^{+}$

BOOKS $66^{+}$

COMPUTER 68

CHICKEN $\quad 86^{+}$

POLICE $76^{+}$

LIGHT 62

MAXIMUM 78

MUSIC $\quad 70^{+}$

BASKETBALL $\quad 64^{+}$

CHILDREN $\quad 78^{+}$

NEW YORK 68

OLD 60

POST 74

ANIMAL $80^{+}$

TEXT $66^{+}$

HELP 70

STATISTICS 60

STATION $86^{+}$

ARMY 64

TELEVISION $\quad 76^{+}$

UNIVERSITY 72 


$\begin{array}{lllllc}\text { UCI } & \text { uci } & \text { uCi } & \text { NSPCC } & \text { CINEMA } & 58 \\ \text { UHT } & \text { uht } & \text { uHt } & \text { BMW } & \text { MILK } & 100^{+} \\ \text {USA } & \text { usa } & \text { uSa } & \text { FM } & \text { AMERICA } & 58 \\ \text { USSR } & \text { ussr } & \text { uSsR } & \text { HSBC } & \text { RUSSIA } & 58^{+} \\ \text {VAT } & \text { vat } & \text { vAt } & \text { LED } & \text { TAX } & 88 \\ \text { VCR } & \text { vcr } & \text { vCr } & \text { ABS } & \text { VIDEO } & 82^{+} \\ \text {VIP } & \text { vip } & \text { vIp } & \text { AOL } & \text { IMPORTANT } & 62^{+} \\ \text {WC } & \text { wc } & \text { wC } & \text { PO } & \text { TOILET } & 74^{+}\end{array}$

+ Related prime that is orthographically illegal

\section{Words}

Primes

Related

Upper

Related Related

Lower

Mixed

ARK ark

BITS bits

BOYS boys

COPS cops

CORE core

DING ding

DONOR donor

EAST east

EDAM edam

ELM elm

ERROR error

FIB

FRY'S

fib

fry's

he

HE

HERE here

HIM him

HIS his

HONG hong

HOT hot

IN in

ITCH itch

JESUS jesus

KINGS kings

LEO leo

LOAF loaf

LOW low

MEN men

MOO moo

MUM mum

NAPE nape

NEW new
aRk

bItS

bOyS

cOps

cOrE

$\mathrm{dInG}$

dOnOr

eAsT

eDaM

eLm

eRrOr

$\mathrm{fIb}$

fRy'S

$\mathrm{hE}$

hErE

hIm

hIs

hOnG

hOt

iN

iTcH

jEsUs

kInGs

1Eo

$1 \mathrm{OaF}$

lOw

$\mathrm{mEn}$

mOo

$\mathrm{mUm}$

$\mathrm{nApE}$

$n E w$
Unrelated

Target

RANT

DING

KINGS

ZEBRA

TROVE

BITS

ERROR

SUET

MUM

$\mathrm{HE}$

DONOR

HIM

ITCH

ELM

HOT

FIB

PING

LOW

HERE

NO

FRY'S

NAPE

BOYS

MOO

NOOK

HONG

NEW

LEO

EDAM

JESUS

MEN
NOAH

PIECES

GIRLS $\quad 80$

ROBBERS $\quad 66$

APPLE $\quad 76$

DONG * $\quad 88$

BLOOD 87

WEST 84

CHEESE $\quad 71$

TREE 78

MISTAKE $\quad 52$

LIE 69

CHOCOLATE 58

SHE 73

THERE $\quad 69$

HER 76

HERS 63

KONG * $\quad 89$

COLD 64

OUT 65

SCRATCH $\quad 67$

CHRIST 68

QUEENS 63

LION 60

BREAD $\quad 77$

HIGH 67

WOMEN $\quad 72$

COW $\quad 70$

DAD 69

NECK $\quad 79$

OLD 


$\begin{array}{llllll}\text { NO } & \text { no } & \text { nO } & \text { IN } & \text { YES } & 71 \\ \text { NOOK } & \text { nook } & \text { nOoK } & \text { LOAF } & \text { CRANNY* } & 75 \\ \text { ON } & \text { on } & \text { oN } & \text { UP } & \text { OFF } & 64 \\ \text { ONE } & \text { one } & \text { oNe } & \text { POD } & \text { TWO } & 63 \\ \text { PEW } & \text { pew } & \text { pEw } & \text { PUP } & \text { CHURCH } & 60 \\ \text { PING } & \text { ping } & \text { pInG } & \text { HIS } & \text { PONG } * & 85 \\ \text { PINS } & \text { pins } & \text { pInS } & \text { RUNGS } & \text { NEEDLES } & 76 \\ \text { POD } & \text { pod } & \text { pOd } & \text { ONE } & \text { PEA } & 66 \\ \text { PUP } & \text { pup } & \text { pUp } & \text { PEW } & \text { DOG } & 63 \\ \text { RANT } & \text { rant } & \text { rAnT } & \text { ARK } & \text { RAVE } & 86 \\ \text { RUNGS } & \text { rungs } & \text { rUnGs } & \text { PINS } & \text { LADDER } & 82 \\ \text { SILL } & \text { sill } & \text { sIlL } & \text { WEB } & \text { WINDOW } & 78 \\ \text { SUET } & \text { suet } & \text { sUeT } & \text { EAST } & \text { PUDDING } & 76 \\ \text { TROVE } & \text { trove } & \text { tRoVe } & \text { CORE } & \text { TREASURE } & 82 \\ \text { UP } & \text { up } & \text { uP } & \text { ON } & \text { DOWN } & 72 \\ \text { WEB } & \text { web } & \text { wEb } & \text { SILL } & \text { SPIDER } & 66 \\ \text { ZEBRA } & \text { zebra } & \text { zEbRa } & \text { COPS } & \text { CROSSING } & 61\end{array}$

